\title{
Development of small-scale wind energy systems adaptable to climatic conditions using chattering torque control - PI pitch control and CAES strategy
}

\author{
N. Luo ${ }^{1}$, T. Pujol ${ }^{1}$, L. Pacheco ${ }^{1}$, J.R. González ${ }^{1}$, J.V. Bramon ${ }^{2}$, A. Massaguer ${ }^{1}$ \\ ${ }^{1}$ Polytechnic School, University of Girona, Campus Montilivi, 17071 Girona (Spain) \\ ${ }^{2}$ Structural Integrity and Composites, Aerospace Engineering, TU Delft, Netherland. \\ Corresponding author: N. Luo, phone number: +0034 972 418888, e-mail: ningsu.luo@udg.edu
}

\begin{abstract}
Small wind turbines are commonly single-turbine installations owned by individual homeowners or farmers for on-site electricity consumption, and are becoming an attractive alternative for off-grid electrification and water pumping, both as stand-alone applications and in combination with other energy technologies such as photovoltaic, small hydro or diesel engines. The cost of energy alone is not the only criterion to consider, other aspects like system performance, suitability for a given wind regime, reliability under normal and extreme wind conditions, efficiency in energy storage and exploitation, and overall system life are often equally important. This research deals with the development of small-scale wind energy systems for increasing the productivity of wind power and achieving the better exploitation of generated energy. The proposed wind turbine controller is based on the variable-speed variable-pitch power regulation strategy, using the combination of chattering torque control and PI pitch control. The hardware-in-the-loop (HIL) simulation and on-site experimental testing in rural area are presented. Compressed air energy storage (CAES) strategy for the energy exploitation is also discussed.
\end{abstract}

\section{Key words}

Wind energy, small wind turbine, variable-speed variablepitch power regulation, compressed air energy storage, hardware-in-the-loop simulation.

\section{Introduction}

Increasing fossil fuel prices, global warming and the ever growing electricity demand will continue to be the three long-term drivers of the small wind industry. The increasing demand for clean and affordable energy all over the world will without doubt lead to an increasing demand for small wind. In particular in the developing countries, small wind can easily and fast contribute to electrify millions of people in rural areas. Today, small wind turbines have the following common applications [1]-[5]: residential, commercial and industrial uses, pastures, farms and remote villages, hybrid systems, pumping, desalination and purification, fishery and recreational boats, portable systems for leisure, remote monitoring, research and education, telecom base stations, etc. Also, the market for small wind turbines has brought new production opportunities to industries that dedicate to the composite products, steel, towers, power electronic equipment, and construction projects, etc.

According to the 2014 World Wind Energy Association (WWEA) Small Wind World Report [2], the technology barriers for small wind turbines in near term are mainly related to the high cost of wind turbines and insufficient product reliability. Consequently, following technology actions are recommended: 1) Reduce costs by new turbine development activity for low wind speed sites and new component development for small wind turbines. 2) Continue focused long-term research unique to small wind turbines furling, durability, blade aerodynamics, noise, and power electronics. 3) Research reliability concerns such as extreme climatic conditions, lightning, alternator winding insulation, corrosion, bearing lubrication, electronics, etc. 3) Develop packages with other distributed generation and storage technologies.

This paper presents our research experience on the development of the power generation control techniques and compressed air energy storage strategies for increasing the productivity, operability, reliability and energy exploitation of small-scale wind energy systems. In Section 2, the variable-speed variable-pitch power regulation strategy is proposed using the combination of chattering torque control and PI pitch control. Section 3 presents the hardware-in-the-loop simulation and the onsite experimental testing with a $2.2 \mathrm{~kW}$ horizontal axis wind turbine installed in a rural area in the municipality of Ordis at the north of Catalonia. In Section 4, some preliminary result related to the compressed air energy storage strategy for energy exploitation is discussed. Some concluding remarks are given in the last section.

\section{Control strategies}

\subsection{System modeling}

The basic components of a horizontal axis wind turbine consist of a rotor assembly, gearbox and generator. The wind turbine rotor extracts the energy from the wind and converts it into mechanical power. 


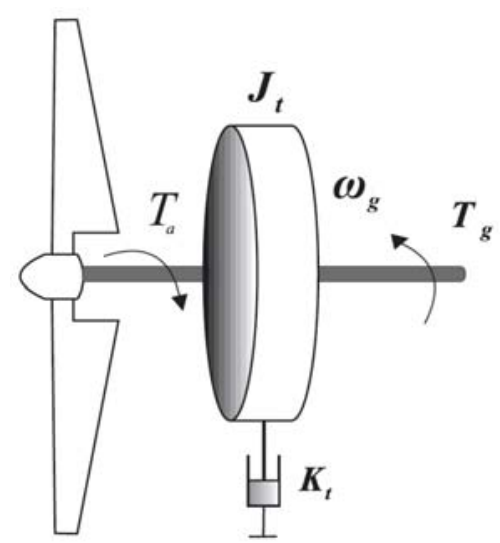

Fig.1. One mass model of a wind turbine

A simplified model of the rotor (Fig. 1), which assumes an algebraic relation between the wind speed $u$ and the extracted mechanical power $P_{m}$, is given as follows:

$$
\begin{gathered}
P_{m}=\frac{1}{2} C_{p}(\lambda, \beta) \rho \pi R^{2} u^{3} \\
\lambda=\frac{R \omega_{g}}{u}
\end{gathered}
$$

where $\rho$ is the air density, $R$ is the radius of the rotor, $u$ is the wind speed, $C_{p}$ is the power coefficient of the wind turbine, $\beta$ is the pitch angle, $\lambda$ is the tip-speed ratio, and $\omega_{g}$ is the rotor speed. It is seen from (1)-(2) that any change in the wind speed or rotor speed will cause changes in the tip-speed ratio and lead to power coefficient variation, which will affect the generated power $P_{m}$.

The aerodynamic torque $T_{a}$ is related to the generated power $P_{m}$ in the following way:

$$
P_{m}=\omega_{g} T_{a}
$$

where

$$
\begin{aligned}
& T_{a}=\frac{1}{2} C_{q}(\lambda, \beta) \rho \pi R^{3} u^{2} \\
& C_{q}(\lambda, \beta)=\frac{C_{p}(\lambda, \beta)}{\lambda}
\end{aligned}
$$

For a perfectly rigid low-speed shaft, the dynamics of a single-mass wind turbine model is described by:

$$
J_{t} \dot{\omega}_{g}=T_{a}-K_{t} \omega_{g}-T_{g}
$$

where $J_{t}$ is the turbine total inertia, $K_{t}$ is the turbine total external damping, and $T_{g}$ is the generator torque.

\subsection{Power curve profile}

It is important to understand the relationship between the power and wind speed to determine the required control type, optimization or limitation [6]. The power curve profile specifies how much power can be extracted from the incoming wind. The cut-in and cut-out speeds are the operating limits of the turbine. By staying in this range, it is ensured that the available energy is above the minimum threshold and structural health is maintained. The rated power, a point provided by the manufacturer, takes both energy and cost into consideration. Also, the rated wind speed is chosen because speeds above this point are rare. Typically, a turbine design that extracts the bulk of energy above the rated wind speed is not cost-effective.

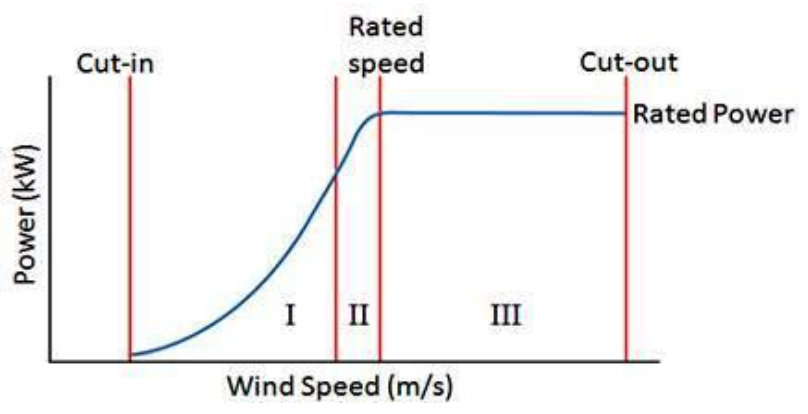

Fig. 2. Ideal wind turbine power curve

In general, the wind turbine power curve is divided into three regions. Region I consists of low wind speeds and is below the rated turbine power, the turbine is run at the maximum efficiency to extract all power. In other words, the turbine controls with optimization in mind. On the other hand, Region III consists of high wind speeds and is at the rated turbine power. The turbine then controls with limitation of the generated power in mind when operating in this region. Finally, Region II is a transition region mainly concerned with keeping rotor torque and noise low.

Controlling the pitch of the blade and speed of the generator are the most effective methods to adjust output power [7]-[11]. Usually, the control strategies use pitch and generator speed control to manage turbine functionality throughout the power curve: fixed-speed fixed-pitch, fixed-speed variable-pitch, variable-speed fixed-pitch, and variable-speed variable-pitch. In our research, the variable-speed variable-pitch control strategy is used in order to theoretically achieve the ideal power curve. Concretely, when controllers operate below the rated wind speed, variable speed and fixed pitch are used to maximize energy capture and increase power quality, and when the controller operates above the rated wind speed, fixed speed and variable pitch permit efficient power regulation at the rated power.

\subsection{Chattering torque control and PI pitch control}

For the variable-speed variable-pitch horizontal axis wind turbines, we have proposed control techniques based on the combination of a nonlinear dynamic chattering torque control strategy and a proportional integral (PI) control strategy for the blade pitch angle [12], in both controllers the generator speed measurement is used as the input information. The above control structure allows for a rapid transition of the wind turbine generated power between different desired values, which implies that it is possible to adjust the wind turbine power production taking into account the power set-point or power consumption. In this way, the electrical power tracking is ensured with high performance behaviors for all other state variables, 
including the turbine and generator rotational speeds, and smooth and adequate evolution of the control variables.

\section{Chattering torque control}

The electrical power-tracking error is defined as

$$
e=P_{a}-P_{r e f} \quad ; \quad P_{e}=\tau_{c} \omega_{g}
$$

where $P_{r e f}$ is the reference electrical power, $P_{e}$ is the measured electrical power, and $\tau_{c}$ is the torque control.

The following chattering torque controller is used, and the theoretic development of control law can found in [13].

$$
\dot{\tau}_{c}=-\frac{1}{\omega_{g}}\left[\tau_{c}\left(a \omega_{g}+\dot{\omega}_{g}\right)-a P_{r e f}+K_{\alpha} \operatorname{sgn}\left(P_{e}-P_{r e f}\right)\right]
$$

with $a>0$ and $K_{\alpha}>0$.

The proposed nonlinear torque control (8) does not require any information on the turbine total external damping or the turbine total inertia, which are physical parameters difficult to obtain. In the implementation of the control law (8) only the measurement of the generator speed and electrical power of wind turbine is needed.

\section{$\underline{\text { PI pitch controller }}$}

While avoiding significant loads and maintaining the rotor speed within the acceptable limits, a pitch angle controller is added to the rotor speed tracking error to assist the torque controller (8) with regulating the wind turbine electric power output. The proposed pitch angle controller is a gain scheduling PI controller with the desired speed and measured speed of the generator as input and the pitch servo angle set-point $\beta$ as output [14]; i.e.,

$$
\beta=K_{p}\left(\omega_{g}-\omega_{n g}\right)+K_{i} \int_{0}^{t}\left(\omega_{g}-\omega_{n g}\right) d t
$$

where $K_{p}>0, K_{i}>0, \omega_{n g}$ is the nominal generator speed, at which the rated electrical power of the wind turbine is obtained. When all pitch angles are measured, the collective pitch angle is obtained by averaging the measurements of all pitch angles. If we want to disable the proportional term when $\omega_{g}<\omega_{n g}$, the following modified pitch angle controller can be used:

$$
\begin{aligned}
& \beta=\frac{1}{2} K_{p}\left(\omega_{g}-\omega_{n g}\right)\left[1+\operatorname{sgn}\left(\omega_{g}-\omega_{n g}\right)\right] \\
& +K_{i} \int_{0}^{t}\left(\omega_{g}-\omega_{n g}\right) d t
\end{aligned}
$$

\section{Experimental testing}

\subsection{Hardware-in-the-loop (HIL) testing}

Following the lead of the auto industry [15], the wind turbine industry has begun moving toward adoption of hardware-in-the-loop (HIL) simulation as a method for real-time testing of embedded control systems during the development phase without using prototypes. On the contrary of computer simulation, HIL simulation uses one or several real components instead of their simulation model, and the other parts of the process are simulated. Such a methodology has been used in aeronautics for a long time [16]. Traction applications are nowadays more and more developed using HIL simulation before the final implementation. One of major benefits of doing HIL simulations is that it allows design engineers to optimize the control system during the development stage, which is going to have a big impact on reliability. Moreover, engineers can take exactly the same code that was used in the simulation and run it directly on the deployed target, saving time and effort in the design process. Finally, the controllers can be tested in extreme cases, such as faults on sensors and/or actuators of the wind turbine. However, testing the above cases experimentally in real case can seriously damage the wind turbine, thus a HIL approach is preferable.

Our HIL testing platform consists of two major parts [17]:

- A laptop runs the wind turbine FAST simulator.

- The wind turbine torque controller, programmed on an Arduino Mega microcontroller board, runs the proposed chattering torque control which is connected to the virtual Wind Turbine via USB.
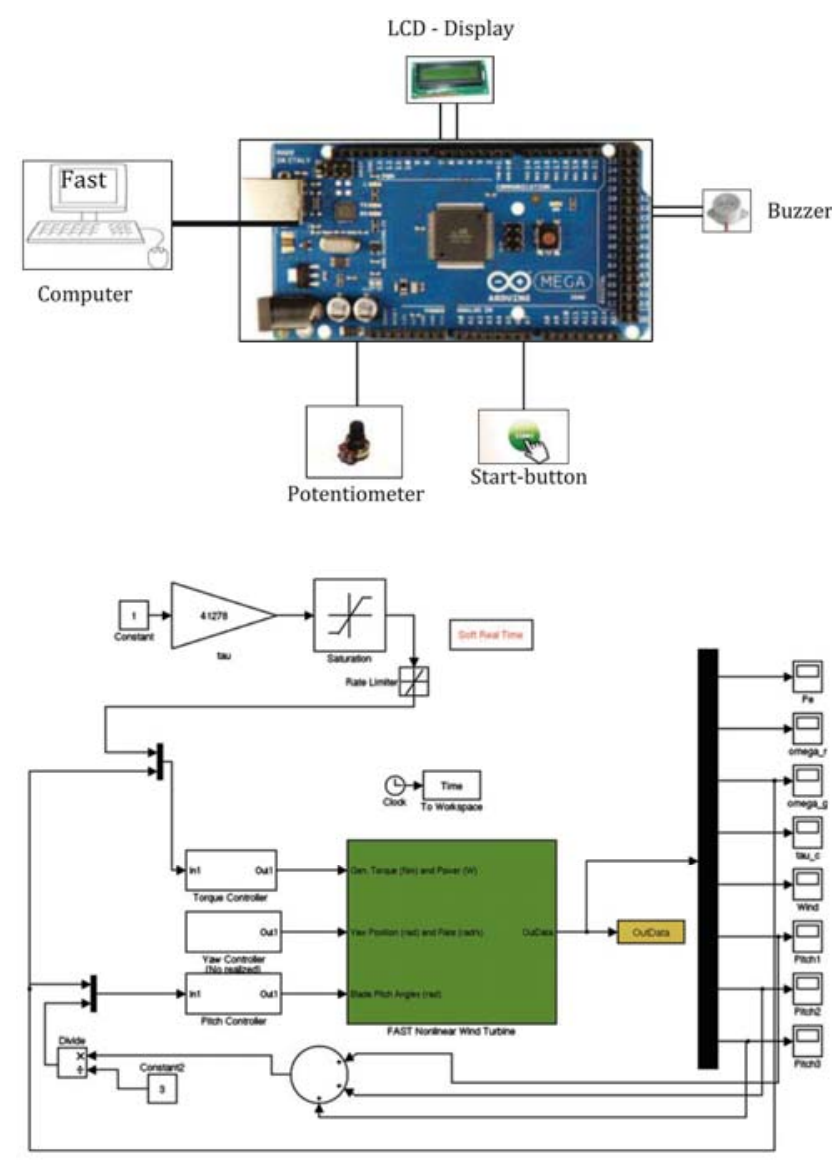

Fig. 3. Block diagram of the HIL experimental setup

The FAST code [18] is a comprehensive aeroelastic simulator capable of predicting the extreme and fatigue loads of two or three-bladed horizontal axis wind turbines. 
An interface between FAST and Simulink is developed with MATLAB, enabling users to implement advanced turbine controls in Simulink convenient block diagram form. The FAST subroutines are linked with a MATLAB standard gateway subroutine so the FAST motion equations (in an S-function) can be incorporated in a Simulink model. This introduces a good flexibility for wind turbine control implementation during simulation. Generator torque, nacelle yaw, and pitch control modules can be designed in the Simulink environment and simulated while using the complete nonlinear aeroelastic wind turbine equations of motion available in FAST simulator. In our research, we have used a laptop with processor Intel Core $\mathrm{i} 5-3230 \mathrm{M}$ to $3.2 \mathrm{GHz}$ and $8 \mathrm{~GB} 2$ SDRAM DDR3 to $1600 \mathrm{MHz}$ to run the FAST simulator. The wind turbine dynamics and wind speed signal have been simulated by the FAST simulator.

We have also used the open-source hardware Arduino Mega2560 microcontroller board in the HIL testing setup. The programming language of Arduino [19] is $\mathrm{C} / \mathrm{C}++$ and a number of libraries make standard applications like printing on an alphanumeric LCD or using serial communication simple. The board can be programmed using a USB-interface, and the program is stored in the internal EEPROM of the microcontroller. Arduino can be used to develop interactive objects, taking inputs from a variety of switches or sensors, and controlling a variety of lights, motors, and other physical outputs.

The HIL setup allows control system hardware Arduino to be connected directly to the FAST simulator. The Arduino receives the inputs of reference power $P_{\text {ref }}$ from the potentiometer and the generator speed $\omega_{g}$ from the FAST simulator and gives the output of the torque controller command to the FAST simulator. The wind inflow for the simulation is given by FAST simulator. The gain scheduled PI pitch control is programmed in the FAST simulator and the chattering torque controller is programmed in the Arduino microcontroller.

The steps to set up the HIL experiment testing are:

- Program, in Arduino language, the torque controller, and download it to the hardware.

- Reconfigure the FAST simulator in Simulink in order to communicate with the hardware inputs and outputs.

- Hardware interface via USB port.

- Set the sampling period of single channel communication management via USB.

- Run Simulink in normal mode. The MATLAB RealTime Sync block allows to synchronize the Simulink model with the real-time clock.

- Run in real-time a fixed-step solver with appropriate step size.

\subsection{On-site experimental testing in a rural area}

A fully sensorized assembly of small wind turbine will be tested in a rural area in a farm located in the municipality of Ordis at the north of the province of Girona, where the wind resource is available during the year and the wind speed is variable and sometime very strong (see Fig.4). Thus, it is an ideal location for doing the experimental testing.

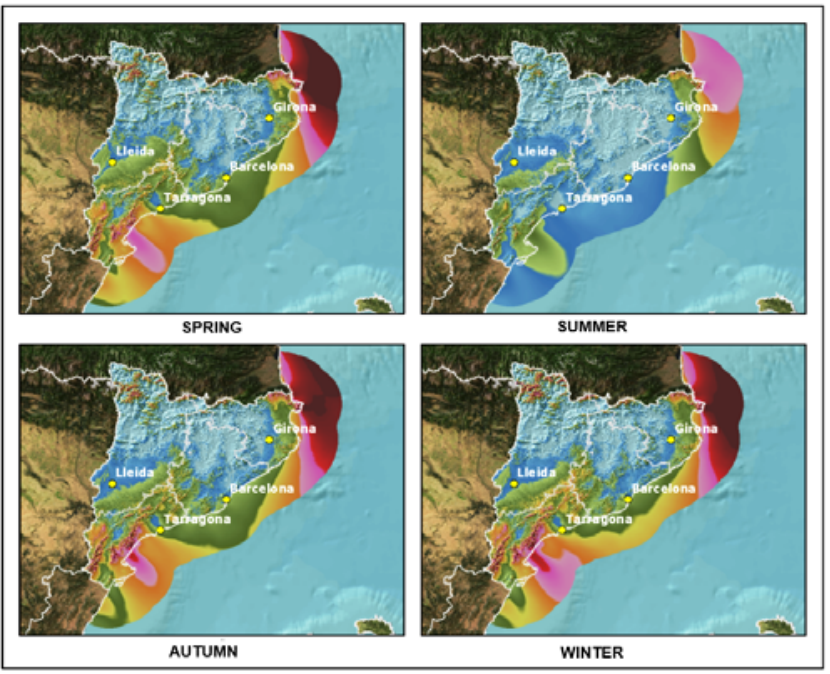

Fig. 4. Wind maps (Girona, Catalonia, Spain)

We have already installed a $2.2 \mathrm{~kW}$ horizontal axis wind turbine in a farm located in Ordis.
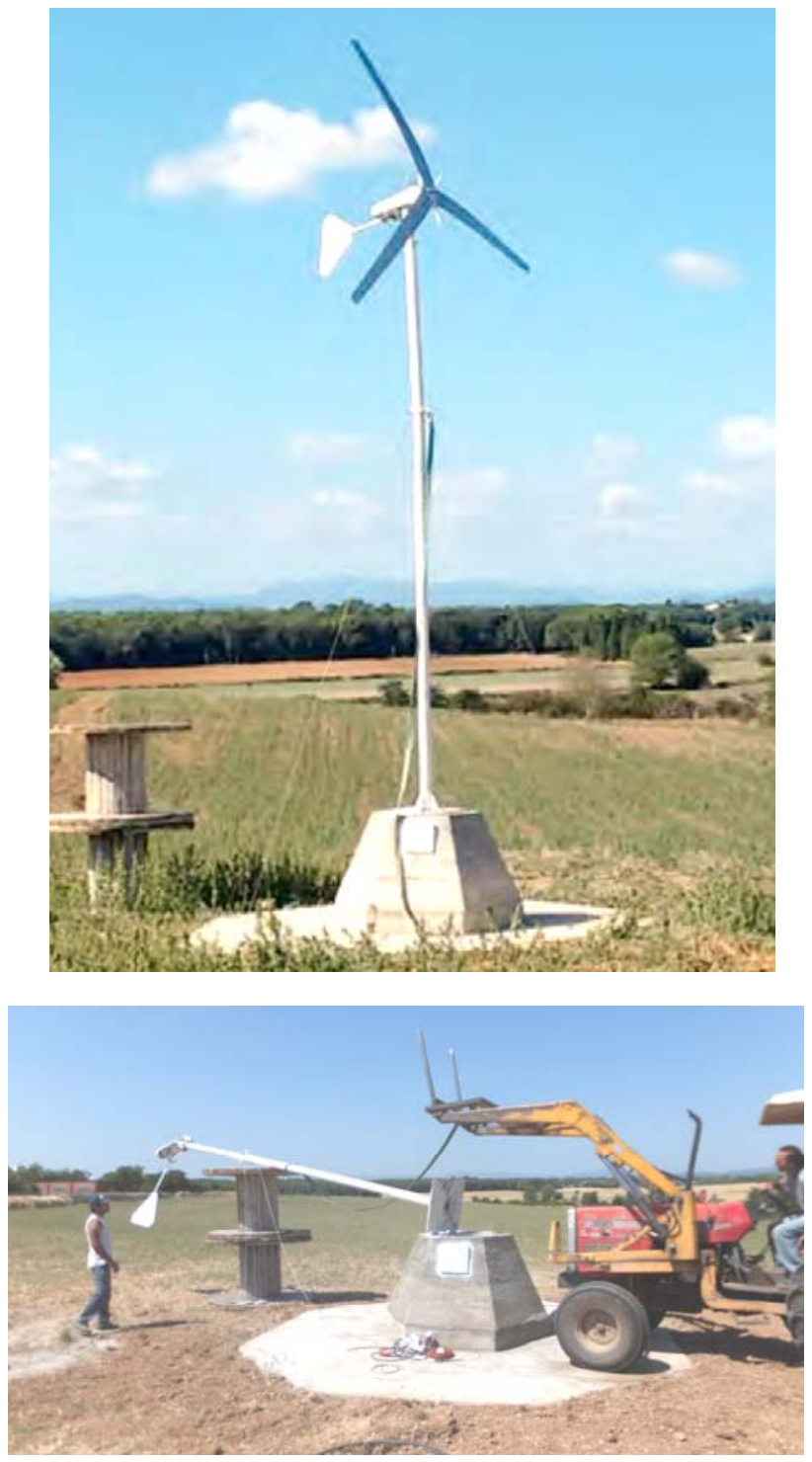

Fig. 5. Small wind turbine installed in a farm located in Ordis 
As part of the experimental assembly, a meteorological station will be installed to evaluate the available energy of the wind resource.

This small wind turbine installation has provided with us an open platform of important research and teaching interests, which permits us to be able to carry out our innovation and research activities and social actions in the following fields:

- Development of new sensing, monitoring and control systems in order to improve the performance of wind energy systems.

- Design and testing of wind turbine blades with aerodynamic shape optimization and new composite materials to meet with the wind conditions.

- Design and testing of active braking systems to regulate the generator speed and pitch systems to optimize the blade position in order to increase wind energy system operability and productivity.

- Design and testing of robust and low-cost tower structures by using new materials and vibration control.

- Design and testing of alternative wind energy storage systems (especially CAES) beyond traditional batteries.

- Evaluation of the combination of solar photovoltaic and wind turbines, overcoming the intermittency of one renewable energy resource with another.

- Evaluation of safety, feasibility and maintenance of wind energy systems.

- Evaluation of site's wind potential methodology and instruments.

- Evaluation of materials used for the different physical structures.

- Evaluation of the developed technological results, as the valuable resources for future transnational research and industrial collaborations.

- On-field demos to increase the social awareness and perception to the profits of small-scale wind energy systems.

\section{Compressed air energy storage (CAES)}

Recently, the complementarities between storage and renewables has become of particular interest, both in terms of capturing enhanced value from such essentially intermittent resources and in maintaining stability in the electrical power system. Nowadays, flywheel, batteries, hydrogen, pumped hydro, compressed air energy storage, electrochemical double layer capacitor, superconducting magnetic energy storage and virtual energy storage systems, are some examples of available energy storage systems [20].

In a wind-based energy system, the general design of the system is focused on increasing the wind energy share in energy production in a cost effective manner. One of new challenges for the wind energy integration to power system is the fact that inherent variability and partly unpredictability of wind cause power fluctuations in the system [21]-[22]. The random nature of the wind speed highlights the necessity of an energy storage system to solve the wind integration issues. One of the actions that can be taken to decrease wind power fluctuations and variability and allow further increase of wind penetration in the wind power system is the integration of energy storage technology.

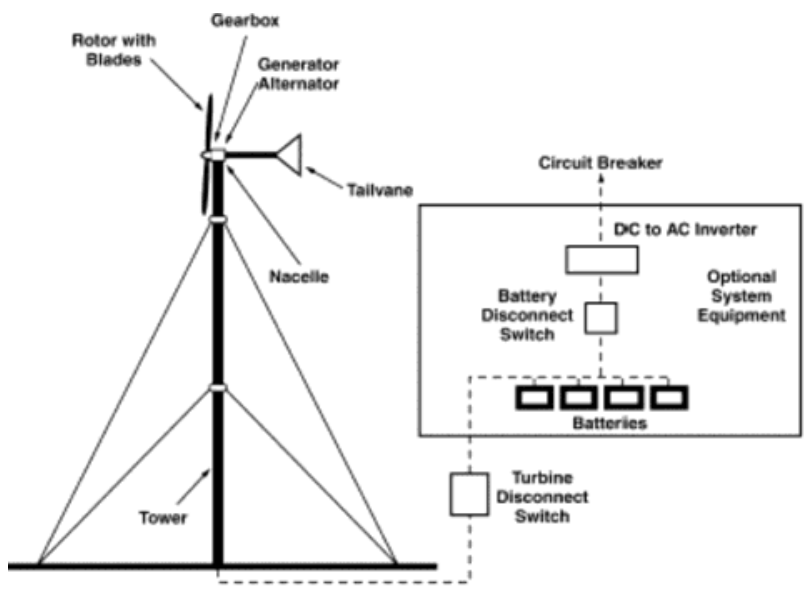

Fig. 6. Wind turbine with battery storage system

The rechargeable battery is one of the most widely used electrical energy storage technologies in the small-scale wind energy systems, as it can be easily used for on-site electricity consumption and engaged with grid through power electronic utilities. However, the rechargeable battery has some weaknesses in low energy density, small power capacity, high maintenance cost, limited cycle life and decreasing health state. Moreover, most batteries contain toxic materials, which may cause environmental harm if they are not recycled properly.

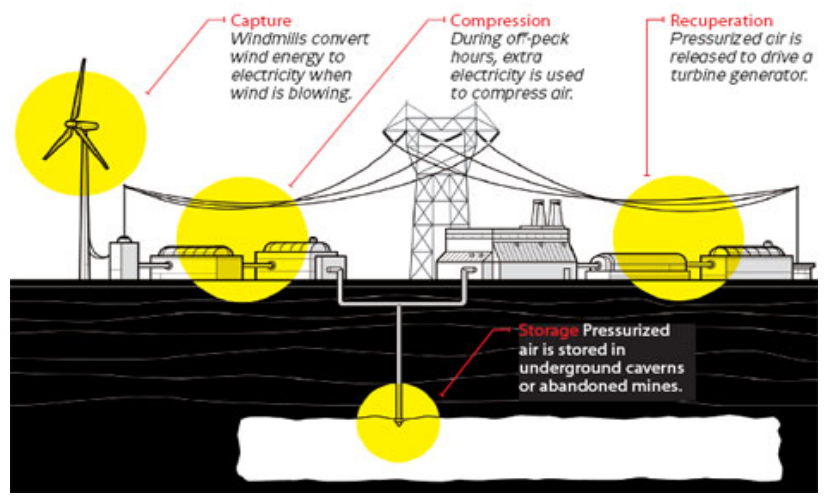

Fig. 7. Wind turbine with CAES system

CAES is a developing technology that has the potential to meet the needs of intermittent sustainable energy sources and high peak load electrical power demands, with a very long service period, low cost of energy, low cost of maintenance and operation, and high power efficiency by storing energy during off peak periods [23]. Recently, CAES has emerged in building a range of small-scale energy storage products. With the hybrid connection to capacitors or supercapacitors to bridge the transient responses, small-scale CAES appeared in the market as an alternative to the rechargeable battery. To the small-scale 
CAES facility, the storage reservoir can use over-ground cylinders or vessels with suitable dimensions. The stored high-pressure compressed air (the pressure can be much higher than that in underground caverns) can be obtained from on-site compression facility or delivered to the site in the form of pre-filled high-pressure air cylinders through the compressed air product supply chain. The air turbine/expander used to drive an electrical generator is the key component in such small-scale CAES facilities which require high efficiency, fast response and low/free maintenance.

Recently, we just started our research activities on the development of new CAES prototypes (see Fig. 8) and the study of the relationship between the CAES energy efficiency, and the aerodynamic torque $T_{a}$ and rotor speed $\omega_{g}$ of the wind turbine.

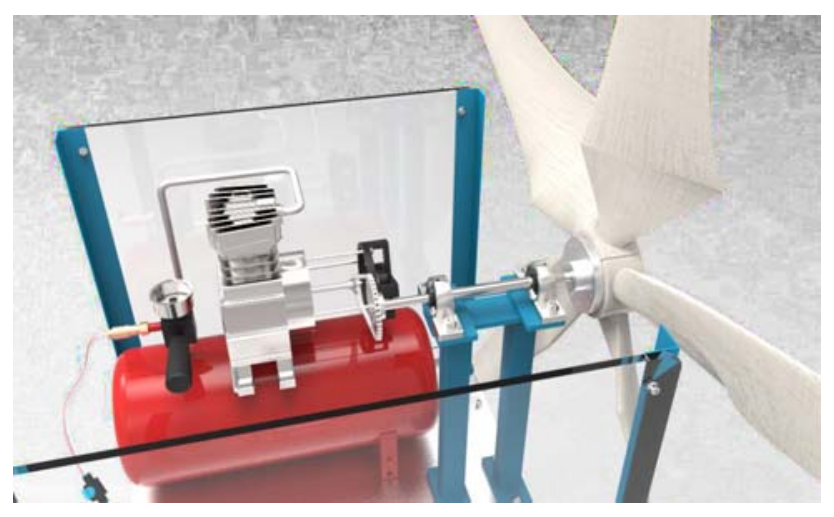

Fig. 8. CAES prototype

\section{Conclusions}

In this paper, chattering torque controller and PI pitch controller have been proposed for achieving the variablespeed variable-pitch wind power regulation. The proposed controllers can be easily used in real-time application because the control design does not need any information on the turbine total external damping or the turbine total inertia, and the implementation of the control laws only requires the measurement of the generator speed and electrical power of the wind turbine. The hardware-in-theloop (HIL) simulation has been an interesting experience for the evaluation of the wind turbine performance under different wind conditions and the verification of the effectiveness of the advanced control techniques. Our future research activities will be centered in carrying out diverse on-site experimental tasks mentioned in the Section 3.2 and continuing with the development of energy efficient CAES technologies.

\section{References}

[1] IRENA - International Renewable Energy Agency (2015), Small Wind Turbines: Quality Infrastructure for Renewable Energy Technologies, Technical Report.

[2] WWEA - World Wind Energy Association (2014), Small Wind World Report.

[3] Renewable UK (2014), Small and Medium Wind Strategy, Technical Report.
[4] A. Bertašienè, B. Azzopardi, Synergies of wind turbine control techniques, Renewable and Sustainable Energy Reviews, 45 (2015) 336-342.

[5] O. Probst, J. Martínez, J. Elizondo, O. Monroy, Small wind turbine technology, Wind turbines, In Tech. 2011.

[6] A. Chehouri, R. Younes, A. Ilinca, J. Perron, Review of performance optimization techniques applied to wind turbines, Applied Energy, 142 (2015) 361-388.

[7] R. Lanzame, M. Messina, Power curve control in micro wind turbine design, Energy, 35(2010) 556-561.

[8] H. Gitano-Briggs, Small wind turbine power controllers, Wind Power, In Tech, 2010.

[9] D. Rivkin, L. Anderson, L. Silk, Wind Turbine Control Systems, Jones \& Bartlett Learning, 2012.

[10] N. Luo, Y. Vidal, L. Acho, Wind Turbine Control and Monitoring, Springer, 2014.

[11] A. Kusiak, W. Li, Z Song, Dynamic control of wind turbines, Renewable Energy, 35 (2010) 456-463.

[12] F Pozo, Y Vidal, L. Acho, N. Luo, M. Zapateiro, Power regulation of wind turbines using torque and pitch control. American Control Conference, 2013.

[13] L. Acho, Y. Vidal, M. Zapateiro, F. Pozo, N. Luo, Chattering control design on a variable-speed horizontalaxis wind turbine, IEEE-IAS SAICA, 2011.

[14] Y. Vidal, L. Acho, N. Luo, M. Zapateiro, F. Pozo, Power control design for variable-speed wind turbines, Energies, 5 (2012) 3033-3050.

[15] H. Hanselmann, Hardware-in-the-loop simulation testing and its integration into a CACSD toolset, Computer-aided control system design, 1996.

[16] D. Macla, Simulation gets into the loop. IEEE Rev., 43 (1997) 109-112.

[17] Y. Vidal, L. Acho, N. Luo, C. Tutiven, Hardware in the loop wind turbine simulator for control system testing, Wind Turbine Control and Monitoring, Springer, 2014.

[18] J. Jonkman, NWTC computer-aided engineering tools (FAST), url: http://wind.nrel.gov/designcodes/simulators/ fast/, 2013.

[19] Arduino (2014), url: http://arduino.cc.

[20] H. Ibrahim, A. Ilinca, J. Perron, Energy storage systems: characteristics and comparisons, Renewable and Sustainable Energy Reviews, 12 (2008) 1221-1250.

[21] H. Zhao, et al., Review of energy storage system for wind power integration support, Applied Energy, 137 (2015) 545-553.

[22] F. Díaz, A. Sumper, O. Gomis, R. Villafáfila, A review of energy storage technologies for wind power applications, Renewable and Sustainable Energy Reviews, 16 (2012) 21542171.

[23] H. Lund, G. Salge, The role of compressed air energy storage (CAES) in future sustainable energy systems, Energy Convers. Manag. 50 (2009) 1172-1179. 